\title{
To Coat or Not To Coat: A question on porosity and coating in building material
}

\author{
Diandra Pandu Saginatari, ${ }^{1, *}$ and Yandi Andri Yatmo ${ }^{2}$ \\ 1,2 Department of Architecture, Faculty of Engineering, Universitas Indonesia, Depok, Indonesia
}

\begin{abstract}
Building material has been one of the aspects in architecture that directly relate with the overall building performance. Nowadays, porous traditional building material, such as bricks, stones, concrete, is still preferred due to its performance of porosity that supports passive cooling and reduces the building's energy consumption. However, the porosity of building material could also cause many problems, such as damp, fungal and moss growth, that could cause deterioration of the building leading to the practice of coating. This paper questions how the act of coating often seen as a way of keeping the building in perfect condition with disregard to the building material's porosity. It investigates how the different mechanism of porosity in building material in turns triggers a different act of coating. Furthermore, this paper argues that the act of coating should consider the performance of porosity to achieve a better building performance, not just regarding the energy efficiency but also the ecological sensibility towards the environment.
\end{abstract}

\section{Introduction}

Building material has been an important architectural aspect that influence energy consumption as part of the building performance. Researches about building material significantly highlight the high and growing building energy consumption, particularly within the cooling process [1-4]. In accordance with this issue, the use of porous material $[2,4-7]$ and the use of coating [1, 8] has become the "passive" alternatives to reduce the energy consumption for thermal control. Nevertheless, the majority of researches on building material and coating tend to solely focus on the technical and physical properties of the building material and coating [1-18]. This paper focuses instead on developing a core understanding of the different kinds of porosity and coating across building materials that influence the building performance.

Some researches address how porous materials provide transporting ability that support passive cooling through evaporation, moisture and heat transfer [2, 4-7, 9-11] while coating supports the thermal control due to its reflectance toward heat source radiation (sunlight) $[1$, 8]. However, in many context, porosity is also considered as the beginning of degradation and deterioration of building material that become the parameter of its durability [12-17]. The porosity of building material is associated with the durability of the material, and coating often becomes the response toward this durability issue.

\footnotetext{
Corresponding author: diandrasaginatari@gmail.com
}

The use of coating to maintain durability is mostly related to avoid water and moisture containment that could generate pathological problems for the building material such as dampness, microbial growth, material loss, etc $[12,15,17-20]$. Coating suggests the act of covering something; in building material, it usually covers the surface. Coating generally aims for protection, mostly against water [13, 17, 18, 21], even though some other aims, such as hygiene [21] and aesthetic $[14,15,19]$ are also relevant. A coating on the surface of porous building material usually decreases the porosity and roughness of the surface $[12,14,19]$ to shield the permeability of the material. It is expected to prevent the water penetration from the surface to the bulk $[13,19]$ and provide a natural cleaning process [12].

The implantation of coating does not always work, as it significantly depends on the condition of the surface, the compatibility of the coating with the material $[12$, 19]. In addition, coating is also influenced by the macro and microclimate of the environment that could affect the performance of the coating. In this sense, it can be argued that the discussion of porosity and coating of building material is significantly related towards a more ecologically sensible architecture. This paper aims to provide an overview about the porosity of building material and the act of coating, conducting a literature review that analyses favourable and unfavourable porosity in building material. It also unravels various acts of coating in response to porosity. This paper then concludes by providing other perspectives on how the discussion about porosity and the act of coating 
contribute towards a better ecologically sensible practice.

\section{Porosity and building material}

Porosity refers to the permeability of the material defined by the spaces within a material that enable distribution of fluid. This ability is the basis for both the favourable and unfavourable porosity in building material. As indicated by some researches [2, 4-7, 9-11], the transporting ability of moisture and heat is favourable for the passive thermal control in the building. Porosity allows exchange between the inside and outside environment. Moreover, in building material, porosity in microscale can absorb and release moisture. Fig. 1. below illustrates how porosity works in evaporating and cooling the temperature.

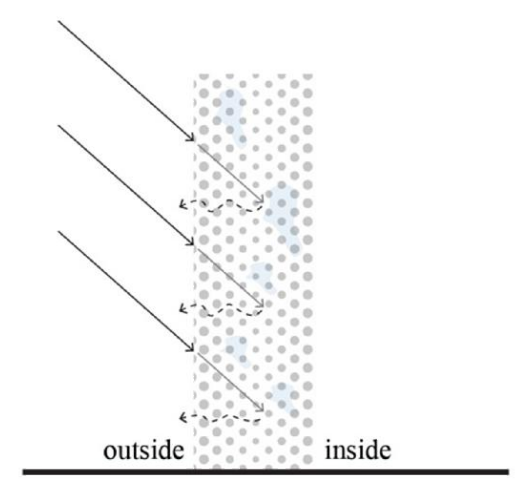

$\underset{k-1, \text { evaporation }}{\longrightarrow}$

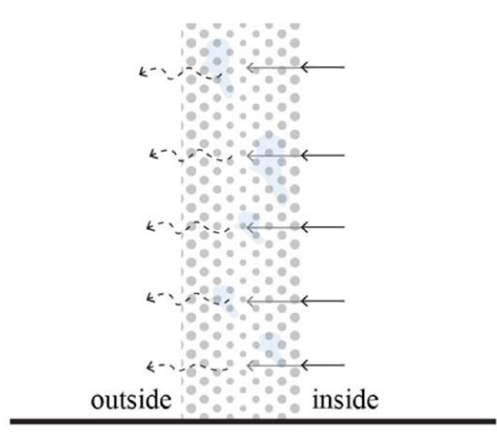

Fig. 1. Evaporation in porous building material

Evaporation is an energy consuming process, it only possible to happen in the presence of heat. The porosity of building material will have the capacity to contain water and absorb water if there is a temperature difference in the environment. Figure 1 shows that, in one case, if one surface of porous material is radiated with heat (i.e. sunlight) that causes different temperature between the two surface significantly, the heat will not reach the inside of the material because the porous material contains water (moisture) and the water will absorb the heat to evaporate. In the other case, if the inside temperature is higher, the water within the material will absorb the heat from the inside to evaporate. These two examples show how porosity influence the overall temperature and gives a cooling effect.

Some researches about building material indicate that higher porosity, with better absorption, will cause better evaporation and cause a better cooling effect [4, 5]. Porous building material arrangements such as breathing walls tries to optimise the porosity of building envelope as heat exchanger [10]. These advantages of porosity in term of cooling and heat exchange seem beneficial for a hot climate. In cold climate, however, porosity is not preferred because of it sufficiency in conducting heat and lacks in retaining heat. Therefore, in cold climate porous building material is avoided and an additional coating is usually applied.

The additional coating for porous building material appears to overcome the unfavourable fact that porosity could alter the durability of the material. As a microstructure, porosity directly relates to the physical structure of the material. The higher the porosity, the weaker the physical structure. However, the primary concern about porosity is the penetration of the water $[12,13,16,19]$. The aqueous (and gaseous) permeability of porous building material is directly related to the durability of the material [16]. Porosity allows water to penetrate. In specific circumstance where the evaporation is not happening, the water within the material will start to affect the material structure. It will start to create dampness and moreover, water and the porosity, together, could invite microbial organisms to start inhabiting the material $[12,15,20]$. Problems such as mould, moss, and surface loss that are caused by water containment within the material could be considered as a pathological symptom of the building [17]. All of these symptoms will start the degradation and decay that leads to the deterioration of the material. This deterioration could be as simple as altering the aesthetical appearance, up to changing and shortening the material life [12].

\section{Coating of porosity}

The dominant paradigm about building material in general is it has to be as water resistant as it can be for the building to last (forever). The building should be kept dry [18], and waterproofing is always considered essential. Unfortunately, the presence of water within a material is inevitable [18]. Depending on the climate, water will always exist, in the form of water such as rain, or others such as moisture. Therefore, coating is expected to help survive this condition and prevent any deterioration. The act of coating becomes part of the maintenance process of the building to keep the building in acceptable condition as we aim for the immortal appearance of our building.

Coating, in any form, is usually applied on the surface of the material. With the purpose of water 
repellency coating reduces the porosity and the roughness of the surface targeting a somewhat smooth surface [19]. The smooth surface, both from the effect of substance coating, such as paint, and the polishing coating, usually increase the runoff of water [19] and reduce surface wettability [13]. Some coating such as paint is also able to prevent the colonisation of a microbial organism $[22,15]$ as coating reduces the bio receptivity of the material that enable the microbial organism to inhabit the material. In general, coating provides appropriate surface porosity that is considered improvement of surface quality $[12,15]$ and leads to a natural or self-cleaning process [12].

In the context of water repellency, there are two types of coating, hydrophobic and hydrophilic coating. The hydrophobic coating is water resistant. In past times, for example, they use organic oil as a coating for building with a vast water exposure such as bath [17]. Nowadays, we could use solvent-based paint and cream emulsion that could make a hydrophobic coating [17, 18]. On the other hand, hydrophilic coating is attracting water. It tends to absorb water so that the water does not reach the bulk of the material.
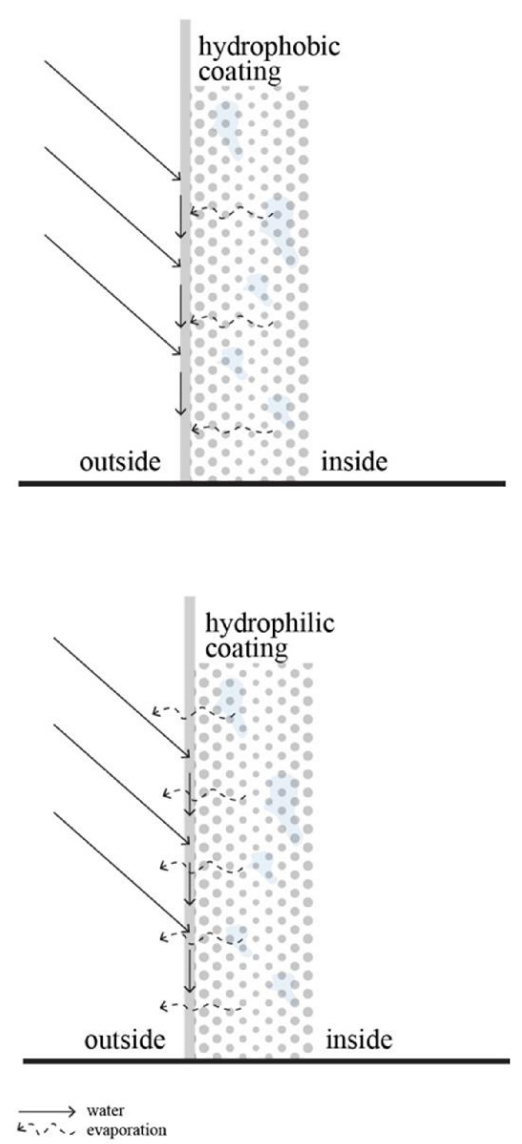

Fig. 2. Hydrophobic and Hydrophilic Coating

Figure 2 illustrates how hydrophobic and hydrophilic coating work. The water repellency of hydrophobic resists water. However, it also reduces the evaporation rate [19]. If by chance water manages to penetrate, due to the failing of hydrophobisation usually on a surface with rough and large pores, the water will not be evaporated through the surface and the water will be trapped in bulk and could worsen the material [22]. In contrast, hydrophilic coating still retain an excellent ability to evaporate the water.

Selecting between hydrophobic and hydrophilic coating depends on the purpose of the coating that relates to the overall condition of the climate and the context. In the cultural heritage setting, for example, coating for the historic building is essential to prevent vandalism that frequently occurs [13]. Graffiti in the historic building could damage the material and leads to costly maintenance. Therefore, prevention using coating is preferable. The coating aims to prevent the staining agent from penetrating to the material [13] that will make the building easier to clean. Concerning the permanence of the coating, especially in conservation, there are two types of coating, the sacrificial and the permanent $[13,23]$. The sacrificial coating, such as wax and silicone [23], is removed during the cleaning and has to be reapplied [13]. The permanent one, such as polyurethanes, fluorocarbon, alkyl alkoxysilane [23], endures the repeated cleaning cycle [13].
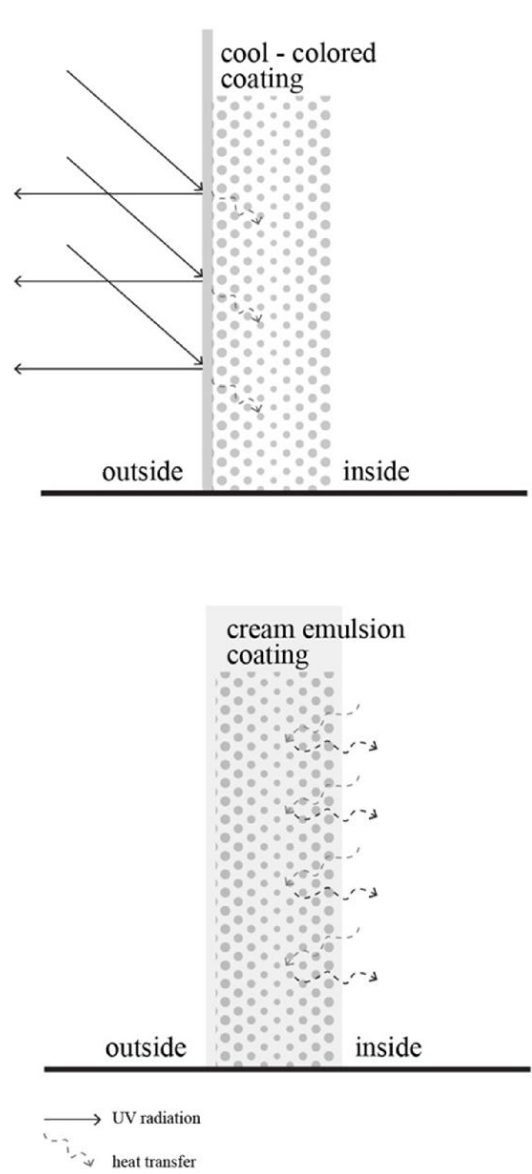

Fig. 3. Coating and Heat Transfer 
Other than water repellency, another aim of coating that is related to repelling and retaining heat, as illustrated in Figure 3 above. Some coating, such as cool coloured coating, has a high solar reflectance and infrared emittance that could reduce the surface porosity absorption of solar radiation [1]. Such coating could also prevent the colonisation of phototroph microbial organism that significantly decreases the reflectance of the material [8]. This kind of coating is suitable for a hot climate environment. As for the cold climate, a coating that could retain heat is more suitable. Using cream emulsion in porous building material, such as brick and mortar, could lower the thermal conductivity that will retain heat within the material [18]. The overall discussion shows that coating seems to be against porosity, no matter what the aim is, be it water or heat repellence or heat retention.

\section{A coating is porous}

If we could project the proper coating for porous building material, it will be the one that is water repellant but also keep a high evaporation rate [19]. One of the examples of such kind of coating is the use of lime coating in the historic building material. Based on this research [19], limewash has many benefits for the conservation of historic building material. Limewash is hydrophilic. It produces a smooth surface that encourages runoff while maintaining the evaporation rate while also being compatible with the building's material. The compatibility of coating with the building material is essential for the maximum performance of the coating $[12,19]$, especially in a historic building where wrong coating could alter the material and could cause further damage. Beside limewash, the coating that is still 'porous' is clay. Clay is hydrophilic. When it is used as a coating, it will absorb the water and prevent it from penetrating to the bulk [17].

Another example is the colonisation of organism such as moss, that could act as a 'porous' coating as well. For example, in this research [24], moss has been an option for an extensive green roof. It has faster cooling process due to its evaporating performance [24]. The colonisation of the organism influencez the microclimate [25] leading to a cooling effect. However, it could also invite other growth that might cause further deterioration.

Research that this study referred [22] states that several microbial organisms, such as fungi, can penetrate pores down to $0.2 \mu \mathrm{m}$. It shows that even a waterresistant coating is porous at some level. Furthermore, as the part that directly exposed to the weather, the coating itself will also deteriorate. In the end, it will open the porosity once more, leading to the need to repeat the act of coating.

\section{Other perspective}

By the time building stands, time and weather will start to degenerate it [26]. This statement reflects this paper's discussion about porosity and coating. Porosity and coating has been explored as part of the effort to make the building in a perfect condition [27]. Porosity, above the advantage in the passive cooling, is recognised for its ability to invite degeneration, decay, and deterioration of building material while the coating is believed to save building form porosity. However, there are moments when coating should give way for porosity to emerge. For an aesthetic reason, some architects and landscape architects preferred a porous moss-grown material [15]. Furthermore, as we are moving towards a more ecological sensible practice, wall ecology becomes one of the examples of allowing porosity to invite colonisation of microorganism [28]. Wall ecology considers the wall surface as an ecosystem that consists of biotic assemblage [28]. The possibility of a wall to become an ecosystem relates to the bio receptivity of the wall surface. Bio receptivity comprises the ability of the material to contribute to the anchorage of organisms that include the capillary porosity of the material [20, 29]. Bio receptivity of a material decreases or resides due to the application of coating $[15,20]$. Bio receptivity demonstrates the "creative capacities" of architecture that opposes the common architectural tendency to be 'waterproof' and 'weather resistance' [20]. Once built, the building will suffer the effect of the location, the corrosive wind, water, sun, will destroy the finishing of the building [30]. However, in this way, the building instead expresses the other dimension of its nature [30].

\section{Conclusion}

Porosity and coating represent the dialogue between building, nature, and human. Both should be used for an ecologically sensible strategy to achieve an ecological building that comforts both human and the environment. Selecting certain material for coating and certain act of coating itself should be based on a thorough understanding of the building material, especially the porosity. Range of building materials may have different performances, that have different responses toward the environment, including the material of coating. Therefore, to coat or not to coat should be answered based on the understanding about porosity and what kind of ecological trajectory that we aimed for. This paper challenges the dominant paradigm that building should be perfect and waterproof. Instead, especially in the harsh tropical climate, this paper demonstrates how knowledge of porosity and coating are important to shift such paradigm towards a more ecological understanding of building for both human and nature.

\section{References}

1. J. Lei, K. Kumarasamy, K.T. Zingre, J. Yang, M.P. Wan, and E.-H. Yang, J. Apenergy, 90, 57-63 (2017)

2. E. Ibrahim, L. Shao, and S. B. Riffat, J. Enbuild, 35(9), 941-949 (2003)

3. P.K. Latha, Y. Darshana, and V. Venugopal, J. Jobe, 3, 104-113 (2015) 
4. L. Zhang, X. Liu, Q. Meng, and Y. Zhang, Energy Efficiency, 9(2), 511-523 (2016)

5. W. Chen, S. Zhang, and Y. Zhang, J. Renene, 115. 1249-1259 (2018)

6. Y. Wang, C. Ma, Y. Liu, D. Wang, and J. Liu, J. ijheatmasstransfer, 125, 330-342 (2018)

7. T.D. Gonçalves, V. Brito; F. Vidigal, L. Matias, and P. Faria, ASCE, 27(8), 04014222-1-04014222-10 (2015)

8. M. A. Shirakawa, A. P. Werle, C. C. Gaylarde, K. Loh, and V. M. John, J. Ibiod, 95, 332-337 (2014)

9. G.H. dos Santos and N. Mendes, J. Ijheatmasstransfer, 52(9-10), 2390-2398 (2009)

10. S. Craig and J. Grinham, J. Enbuild, 149, 246-259 (2017)

11. L. Dutra, N. Mendes, and P. Philippi, Journal of Building Physics, 41(3), 247-263 (2017)

12. O. Rudic, D. Rajnovic, D. Cjepa, S. Vucetic, and J. Ranogajec, J. Ceramint, 41(8), 9779-9792 (2015)

13. M. Lettieri and M. Masieri, J. Apsusc, 288, 466-477 (2014)

14. M. Urosevic, E. Sebastián, and C. Cardell, J. Enggeo, 154, 131-141 (2013)

15. C. Udawattha, H. Galkanda, I. S. Ariyarathne, G. Y. Jayasinghe, and R. Halwatura, J. Buildenv, 137, 268-279 (2018)

16. D. Grover, C.R. Savidge, L. Townsend, O. Rosario, L.B. Hu, D.M Rizzo, and M.M. Dewoolkar, J. Conbuildmat, 112, 1088-1100 (2016)

17. M. Stefanidou and A. Karozou, J. Conbuildmat, 111, 482-487 (2016)

18. J. MacMullen, Z. Zhang, E. Rirsch, H. N. Dhakal, and N. Bennett, J. Enbuild, 43(7), 1560-1565 (2011)

19. T. Diaz Gonçalves, V. Brito, and J. Musacchi, J. Conbuildmat, 57, 179-189 (2014)

20. J.M. Jacobs, S. Cairns, Building Must Die: A Perverse View of Architecture (2014)

21. U. Poershke, ARQ, 17(2), 149-156 (2013)

22. D. Barnat-Hunek, P. Smarzewski, and Z. Suchorab, J. Conbuildmat, 111, 275-285 (2016)

23. V. Gomes, A. Dionísio, J.S. Pozo-Antonio, J. Porgcoat, 113, 90-109 (2017)

24. M. A. A. K., Y. Katoh, H. Katsurayama, M. Koganei, and M. Mizunuma, J. Enbuild, 158, 14171428 (2018)

25. A.K. Mishra, K.K. Jain, K.L. Grag, The Science of the Total Environment, 167, 375-392 (1995)

26. D.P. Saginatari, A. Apti, and P. Atmodiwirjo, Push Away the Building, Long Live, the Plants!, UIA 2017 Seoul World Architects Congress, Seoul, South Korea (2017)

27. R. Handa, Allure of the Incomplete, Imperfect, and Impermanent: Designing and appreciating architecture as nature (2015)
28. R.A. Francis, Progress in Physical Geography, 35(1), 43-63 (2010)

29. O. Guillitte, the Science of the Total Environment, 167, 215-220 (1995)

30. D. Leatherbarrow, Architecture Oriented Otherwise (2009) 